CLINICAL STUDY

\title{
AcroBel - the Belgian registry on acromegaly: a survey of the 'real-life' outcome in 418 acromegalic subjects
}

\author{
Marie Bex, Roger Abs ${ }^{1}$, Guy T’Sjoen ${ }^{2}$, Jean Mockel $^{3}$, Brigitte Velkeniers ${ }^{4}$, Katja Muermans ${ }^{6}$ and Dominique Maiter $^{5}$ \\ Department of Endocrinology, University Hospital Leuven, Leuven, Belgium, ${ }^{1}$ Department of Endocrinology, University of Antwerp, Antwerp, Belgium, \\ ${ }^{2}$ Department of Endocrinology, Ghent University Hospital, Ghent, Belgium, ${ }^{3}$ Department of Endocrinology, University Hospital Erasme, Brussels, \\ Belgium, ${ }^{4}$ Department of Endocrinology, AZ VUB, Brussels, Belgium, ${ }^{5}$ Department of Endocrinology, UCL St Luc, Brussels, Belgium and ${ }^{6}$ Medical \\ department, Novartis Pharma Belgium, Brussels, Belgium
}

(Correspondence should be addressed to M Bex who is now at Department of Endocrinology, University Hospital Gasthuisberg, Herestraat 49 , 3000 Leuven, Belgium; Email: marie.bex@uz.kuleuven.ac.be)

\begin{abstract}
Objectives: To constitute a registry on acromegaly, AcroBel, to evaluate the epidemiology and quality of care of acromegaly in Belgium and Luxembourg.

Design: A nationwide survey from June 2003 till September 2004 aiming to collect data from all patients with acromegaly who had visited the participating endocrine clinics after 1 January 2000. Methods: Retrospective data collection coupled to a visit within the survey period, allowing sampling of metabolic parameters and centralised determination of GH and IGF-I.

Results: Four hundred and eighteen patients $(51 \% \mathrm{men})$ were included, of which 96 were new cases, giving a mean incidence of 1.9 cases per million (c.p.m.) per year. The global prevalence was 41 c.p.m. but varied between 21 and 61 among different areas. Twenty-eight deaths were reported at a median age of 68 years in men and 74 years in women. The standardised mortality rate was significantly increased only in irradiated patients (2.70; confidence interval 1.60-4.55). Central measurements were available in $316(75 \%)$ patients. Mean GH was $\leq 2 \mu \mathrm{g} / \mathrm{l}$ in $65 \%$ and IGF-I was normal for age in $56 \%$, while both criteria were fulfilled in $49 \%$. Multimodal treatment was more effective than primary medical therapy, since $56.5 \%$ were controlled versus $24.3 \%(P<0.0001)$.

Conclusions: AcroBel provides an excellent tool to analyse the prevalence, incidence, treatment modalities and outcome of acromegaly in Belgium. This real-life survey reveals that only half of acromegalic patients received an adequate therapy resulting in cure or disease control when stringent biochemical criteria are used.
\end{abstract}

European Journal of Endocrinology 157 399-409

\section{Introduction}

Acromegaly is a rare disease associated with significant morbidity and an increased mortality rate, resulting from prolonged growth hormone (GH) hypersecretion and excessive production of insulin-like growth factor-I (IGF-I) (1). Depending on the study, control of GH (2-6) and/or normalisation of IGF-I (6-9) are associated with a reversal of the increased mortality and a near normalisation of life expectancy. The aims of therapy and criteria for cure have been previously defined in a consensus statement (10).

Because of the low incidence of the disease, several registries on acromegaly $(3,4,11-13)$ or pituitary tumours (14) have been initiated to collect outcome data on larger cohorts of patients. Most of these registries have been restricted to centres of expertise and may thus not provide a 'real-life' picture of the outcome of acromegaly. Indeed, as in Belgium, the care of acromegalic patients is often dispersed over many academic and non-academic hospital settings. Moreover, outcome analysis in all but one (4) reported databases has been hampered by the use of different $\mathrm{GH}$ and IGF-I assays among participating centres, precluding a valid evaluation of the quality of care.

We invited all endocrinologists involved in the care of patients with pituitary disorders in Belgium and the Grand Duchy of Luxembourg (GD-Luxembourg) to participate in a nationwide survey named AcroBel, that aimed to include all patients with acromegaly under their supervision since 1 January 2000. The primary objectives of our study were to describe the demography and epidemiology of acromegaly and to evaluate the quality of care. A centralised GH and IGF-I measurement service was provided to allow a standardised evaluation of the level of hormonal control. In this first AcroBel publication, we describe the database and report on epidemiology, co-morbidity, mortality and effectiveness of treatments used in acromegaly in a prepegvisomant era. 


\section{Subjects and methods}

\section{Centre participation}

Sixty-four endocrinologists from 37 different hospital settings in Belgium and GD-Luxembourg included a total of 418 acromegalic patients. Three university hospitals were responsible for $42 \%$ of the patients (53, 57 and 65 patients respectively). An additional $20 \%$ was taken care of by physicians from two other universities and one larger regional hospital $(24,29$ and 32 patients respectively). Another six centres were responsible for $17 \%$ (between 9 and 16 patients), while the care of the remaining $21 \%$ was dispersed over 25 centres (between 1 and 6 patients). The Department of Endocrinology of the University Hospital (CHU) of Liège and some local centres declined participation, so the reported data therefore included few patients of the provinces of Liège and Luxembourg, meaning that the majority of the patients were recruited in the remaining eight Belgian provinces, Brussels-Capital (B-Capital) and GD-Luxembourg (Fig. 1), in addition to a few patients from other countries being treated in Belgium. Before implementation, the survey protocol had been approved by the Ethics Committee of the University Hospital of Leuven, and written informed consent was obtained from participants.

\section{Patient selection}

The study was conducted between 15 June 2003 and 30 September 2004 and included all acromegalic patients seen after 1 January 2000, including those who had died before the survey period (deceased group) and those who did not attend the clinic within the survey period (lost-to-follow-up group). Patients were

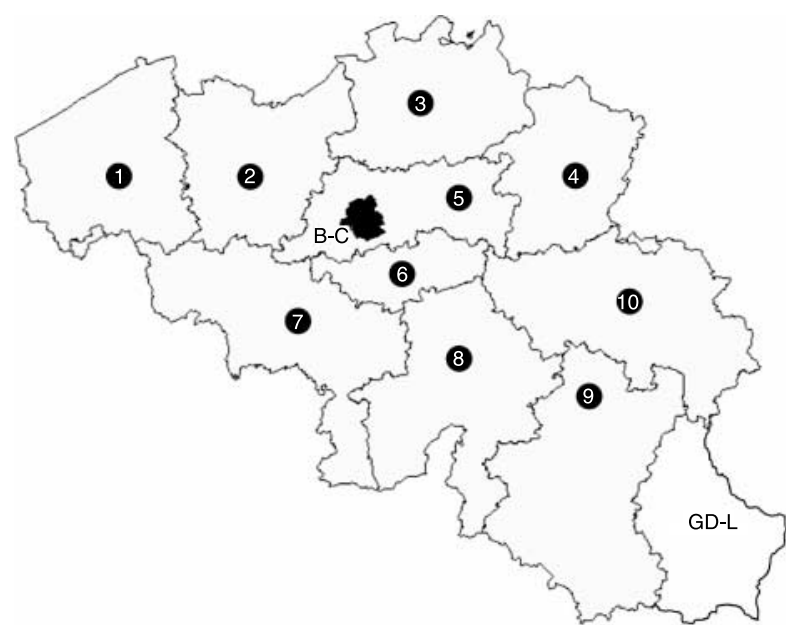

Figure 1 Map showing the different provinces of Belgium, BrusselsCapital and Grand Duchy of Luxembourg. Numbers and abbreviations refer to the provinces in Table 1. identified by a unique number and double reporting was excluded by comparing demographic (date of birth, gender and postcode) and diagnostic (year of diagnosis) data. Diagnosis of acromegaly was confirmed by failure of $\mathrm{GH}$ suppression to $<1 \mu \mathrm{g} / \mathrm{l}$ after glucose loading $(n=34)$, an elevated IGF-I $(n=96)$ or both criteria $(n=204)$. In 22 cases, only elevated mean or random $\mathrm{GH}$ values were reported. In the remaining 62 patients, of whom 48 were diagnosed before 1990, details of biochemical confirmation were no longer available or not provided. However, the clinical diagnosis of acromegaly with radiological evidence of a pituitary tumour was obvious in all these patients and confirmed by surgery in 37 of them.

\section{Data collection}

Data on tumour pathology (pure GH, mixed GHprolactin (PRL), other mixed, ectopic GH-releasing hormone (GHRH) and genetic syndromes), size (microadenoma, macroadenoma, hyperplasia) and invasiveness (yes or no) were collected, as were details of previous treatment: date(s) and route(s) of surgical treatment(s), date(s), method(s) and dose of radiotherapy and types of medical treatment (dopaminergic drugs, somatostatin analogues and $\mathrm{GH}$ receptor antagonists). Morbidity related to the disease or to its treatment: diabetes mellitus, hypertension, arthropathy, carpal tunnel syndrome, sleep apnoea, cardiovascular disease (coronary artery disease, cardiomyopathy with or without valvular insufficiency and atrial arrhythmia), cerebrovascular disease, gallstones, cholecystectomy, goitre, colonic polyps, other neoplasms, visual field defect and

Table 1 Prevalence of acromegaly on 1 January 2004 and mean yearly incidence of acromegaly during the period 2000-2004, according to the residence of the patients in the Belgian provinces or Grand Duchy of Luxembourg and based on the official population number on 1 January 2004.

\begin{tabular}{lrrcc}
\hline & Cases & $\begin{array}{c}\text { Prevalence } \\
\text { c.p.m. }\end{array}$ & $\begin{array}{c}\text { Incidence } \\
\text { c.p.m./year }\end{array}$ \\
\hline $\begin{array}{l}\text { Overall } \\
\text { Flemish region }\end{array}$ & 418 & $40^{\mathrm{a}}$ & $1.9^{\mathrm{a}}$ \\
$1 \quad$ & West Flanders & 26 & 21 & 1.6 \\
2 & East Flanders & 63 & 44 & 1.7 \\
3 & Antwerp & 106 & 59 & 1.6 \\
4 & Limburg & 36 & 43 & 1.2 \\
5 & Brabant Flemish & 46 & 42 & 2.3 \\
Walloon & region & & & \\
6 & Brabant Walloon & 22 & 58 & 3.9 \\
7 & Hainaut & 44 & 34 & 2.0 \\
8 & Namur & 17 & 35 & 3.1 \\
9 & Luxembourg & 3 & & \\
10 & Liège & 8 & & \\
B-C & Brussels-capital & 28 & 28 & 2.0 \\
GD-L & Grand Duchy of & 13 & 29 & 0.9 \\
& $\quad$ Luxembourg & & & \\
\multicolumn{7}{l}{ Other countries } & 6 & & \\
\hline
\end{tabular}

${ }^{\mathrm{a}}$ In Belgium, excluding provinces 9 and 10 that were underrepresented. 
pituitary deficiencies, was reported on a checklist (yes, no or unknown), including year of appearance. No diagnostic criteria were requested although for neoplasms, nature (benign, malignant) and pathology had to be specified. Dates and results of the most recent gallbladder ultrasound, pituitary magnetic resonance imaging (or computed tomography), colonoscopy (or colon radiography) and visual field examination could be reported. Finally, data collection included year and cause of death or date of last visit in patients alive on 1 January 2000 but not attending the clinic during the survey.

\section{Clinical assessment}

At the survey visit, vital parameters (height, weight, blood pressure and pulse rate) and smoking status were recorded. A symptom assessment evaluating the presence and severity (mild, moderate and severe) of headaches, sweating, soft tissue swelling, fatigue and joint pain was performed and expressed as a score (0-15, with higher values denoting more symptoms). Quality of life was also evaluated by a validated questionnaire evaluating 22 items of specific interest to patients with acromegaly, the AcroQoL (grading 0-100 with higher values expressing better quality of life) (15). The quality of life results are the topic of a separate publication (16). Details of current medical treatment for acromegaly (type, name, dosing and start date), diabetes (diet, oral drugs or insulin), hyperlipidaemia or possible GH deficiency (including last IGF-I value before start of $\mathrm{GH}$ replacement therapy), and of sex hormone therapy (gonadal replacement, oral contraceptives, anti-oestrogens and selective oestrogen receptor modulators) were collected. Blood sampling included parameters of carbohydrate and lipoprotein metabolism (glucose and HbA1c, lipids), PRL in mixed GH-PRL secreting tumours and biochemical assessment of disease activity (GH and IGF-I).

\section{Biochemical assessment}

Patients attended the clinic in the morning after an overnight fast, and blood was sampled for local determination of IGF-I (single value) and GH (as a mean of three values, taken at intervals of $15 \mathrm{~min}$ ). To allow uniformity of biochemical outcome parameters, investigators were asked to provide serum samples for additional centralised determinations of IGF-I (one sample) and GH (three samples). These samples were frozen at $80^{\circ} \mathrm{C}$ in the individual centres for later transport to a central laboratory (UCL Saint Luc, Brussels, Belgium). Serum GH and IGF-I concentrations were determined centrally by automated immunoassays (Advantage, Nichols Institute, San Juan Capistrano, CA, USA). The sensitivity of the GH assay was $0.1 \mu \mathrm{g} / \mathrm{l}$ and the intra-assay and inter-assay coefficients of variation were 4.8 and $5.8 \%$ respectively. $\mathrm{GH}$ values were expressed in terms of the WHO RP 80/505, in use at the time of the assay (conversion factor for expression in terms of the second WHO international standard (IS) $98 / 574$ as provided by Nichols $=\mathrm{GH}$ concentration $\times 0.56$ ). The sensitivity of the IGF-I assay was $6 \mu \mathrm{g} / \mathrm{l}$ and the intra-assay and inter-assay coefficients of variation were 5.2 and $5.7 \%$ respectively. All determinations were made at the end of the survey period in two consecutive runs for $\mathrm{GH}$ and in one run for IGF-I. IGF-I values were compared with age- and gender-specific reference ranges, as reported by Brabant et al. (17), and were expressed as a Z-score (normal range -2 to +2$)$.

\section{Outcome analysis: definitions}

Outcome analysis was restricted to the patients with central determinations of GH and IGF-I. Cure was defined by the stringent criteria of both normalised IGF-I for age and gender (Z-score $\leq 2$ ) and a mean GH value $\leq 2 \mu \mathrm{g} / \mathrm{l}$, as a result of previous surgery and/or radiotherapy. Controlled disease was defined by the same criteria obtained under medical therapy irrespective of previous pituitary surgery or radiotherapy. Active disease was defined as both an IGF-I Z-score $>2$ and a mean $\mathrm{GH}$ value $>2 \mu \mathrm{g} / \mathrm{l}$. Patients with discordant IGF-I and $\mathrm{GH}$ values were considered not controlled, with the exception of operated patients with a normal IGF-I and a mean $\mathrm{GH}>2 \mu \mathrm{g} / \mathrm{l}$ but with previous documentation of a $\mathrm{GH}$ nadir after an oral glucose load $<1 \mu \mathrm{g} / \mathrm{l}$ or a random $\mathrm{GH}$ at least once below the detection limit of $0.5 \mu \mathrm{g} / \mathrm{l}$. Patients in whom pituitary surgery and/or radiotherapy had resulted in $\mathrm{GH}$ deficiency and who were on GH replacement therapy were also considered to be cured. In patients treated with the GH receptor antagonist pegvisomant $(n=4)$, IGF-I was the only criterion used.

\section{Data management}

A team of endocrinologists (the AcroBel Scientific Steering Committee) designed the concept of the database, which is owned by the Belgian Endocrine Society. Participating endocrinologists entered their patient's data anonymously in individual personal digital assistants. The software program was developed by MedEurope B V (Hilversum, The Netherlands). Data were subsequently transferred to an Access database managed by one (MB) of the members of the committee. The AcroQol questionnaires were collected centrally and the results were entered directly into the database, as were the centrally determined IGF-I and GH values. After the survey period and complete data entry, the database was scrutinised for inconsistencies and missing data by the database manager and queries were sent to the reporting endocrinologists for clarification and completion. 


\section{Statistical analysis}

To compare the mortality between the survey population and the general population, the standardised mortality ratio (SMR) was calculated as the ratio of observed deaths to the number of expected deaths, based on the person-years follow-up for each sex and age group. Confidence intervals $(\mathrm{CI})$ and $P$ values were calculated by use of logarithmic transformation. The S.E.M. of the natural logarithm of the SMR is 1 divided by the square root of the observed number of deaths, while the $P$ value is obtained using the normal approximation in which the S.D. is 1 divided by the square root of the expected number of deaths.

Standard mortality data for the general Belgian population were obtained from the Federal Public Service Economy - Statistics Division (www.statbel.fgov.be). Since life expectancy is higher in the Flemish region and lower in the Walloon region when compared with the life expectancies in B-Capital and GD-Luxembourg (which are close to the Belgian national average), the corresponding regional mortality data for the period 2001-2003 were used as reference. Comparison of means between two continuous variables with a normal distribution was performed by the Student's $t$-test. The $\chi^{2}$-test was used to test the difference between categorical variables. A $P$ value $<0.05$ was considered statistically significant.

\section{Results}

\section{Population}

Data were available from 418 acromegalic subjects, of which $51 \%(n=213)$ were males and $49 \%(n=205)$ were females, with a median age at diagnosis of 42 (range 8-81) and 46 (range 17-80) years respectively. From January 2000 onwards, 96 patients were newly diagnosed with acromegaly. About $86 \%(n=362)$ of the patients actively participated in the survey. The mean duration of follow-up was 11 years (s.D. 9, range 0-45). Of the remaining patients, 25 had died by June 2003 and 31 were lost to follow-up.

\section{Prevalence and incidence}

The global prevalence of acromegaly was 40 cases per million (c.p.m.), by comparing the number of patients alive 1 January 2004 in each of the eight Belgian provinces and B-Capital $(n=368)$ with the total population of these provinces on that date provided by the National Institute of Statistics (Table 1). Prevalence varied widely from 21 to 59 c.p.m. among the provinces. If the highest prevalence of 59 c.p.m. recorded in the densely populated province of Antwerp is extrapolated to the total population of Belgium and GD-Luxembourg (10.85 million), a maximum of 640 cases would be expected on 1 January 2004. We thus assume to report outcome data on at least $61 \%$ of all living Belgian acromegalic patients, $73 \%$ of cases in the Flemish region and $46 \%$ in the Walloon region, B-Capital and GD-Luxembourg.

The mean incidence over the period 2000-2004 based on the newly diagnosed patients residing in Belgium with exclusion of the provinces Liège and Luxembourg $(n=88)$ was 1.9 c.p.m. per year. A similar mean incidence was calculated over the period 1990-1999.

\section{Aetiology}

Overall, $79 \%(n=330)$ of patients harboured a macroadenoma $(>10 \mathrm{~mm}$ in diameter) and $16 \%$ $(n=65)$ a microadenoma. The tumour size was unknown in 19 cases, while 4 had pituitary hyperplasia due to ectopic GHRH secretion $(n=3)$ or McCuneAlbright syndrome $(n=1)$. Over the last 5 years, the proportions of macroadenomas and microadenomas were 76 and $23 \%$ respectively.

In eight cases, the diagnosis was made during childhood or adolescence (age 8-18). Four patients had multiple endocrine neoplasia type 1 . Two patients, one with hyperplasia and other with macroadenoma, presented with McCune-Albright syndrome. Two patients (first cousins) had isolated familial somatotropinoma. Seventy-two percent $(n=299$, of which 55 had microadenomas) had pure $\mathrm{GH}$ producing adenomas, while co-secretion of PRL was reported in $21 \%(n=90$, of which five had microadenomas) and co-secretion of other hormones (a-subunit and/or thyrotrophin (TSH)) in $1 \%(n=4)$. The tumour type could not be specified in 22 cases.

\section{Morbidity}

The prevalence of associated morbidity is shown in Table 2. Arthropathy was most frequently reported, followed by hypertension, carpal tunnel syndrome, diabetes mellitus and goitre. Patients with diabetes were on average 10 years older than non-diabetics. Seventy percent of diabetics were on hypoglycaemic agents (47\% oral, 19\% insulin and 5\% both). Diabetes was well controlled (HbAlc $\leq 6.5 \%$ ) in $47 \%$ and poorly controlled (HbAlc $\geq 8 \%$ ) in $20 \%$ of the 90 patients in whom $\mathrm{HbA1c}$ was reported.

Cholecystolithiasis and sleep apnoea syndrome were probably underreported as specific testing was frequently lacking. The prevalence of gallstones was four times higher in somatostatin analogue-treated patients versus non-treated patients (31 vs $8 \% ; P<0.001)$. Forty-one percent of patients with known gallstones had undergone a cholecystectomy.

In 61 out of 74 patients with cardiovascular disease, the diagnosis was specified: cardiomyopathy, atrial arrhythmia or ischemic heart disease was present in 30,19 and 31 cases respectively, alone $(n=46)$ or in different combinations $(n=15)$. Lipid values were available in 362 
Table 2 Reported morbidity in the total cohort ( $n=418$ patients).

\begin{tabular}{lcl}
\hline Complication & Prevalence $(\%)$ & Reported cases \\
\hline Diabetes mellitus & 25.3 & $105 / 415$ \\
Hypertension & 39.4 & $161 / 409$ \\
Arthropathy & 46.7 & $188 / 403$ \\
Carpal tunnel & 28.1 & $114 / 406$ \\
Sleep apnoea & 17.1 & $58 / 339$ \\
Cardiovascular & 18.0 & $74 / 412$ \\
Cerebrovascular & 5.7 & $23 / 407$ \\
Gallstones & 23.4 & $83 / 355^{\mathrm{a}}$ \\
Cholecystectomy & 8.3 & $34 / 411$ \\
Goitre & 24.2 & $99 / 409$ \\
Colonic polyps ${ }^{\mathrm{b}}$ & 27.2 & $77 / 283^{\mathrm{a}}$ \\
Any hormonal deficiency & 39.7 & $163 / 411$ \\
$\geq 3$ deficiencies & 16.3 & $67 / 411$ \\
Visual field defect & 15.4 & $63 / 410$
\end{tabular}

an patients reported free of gallstones or colonic polyps, definitive report of normal gallbladder ultrasound or colonoscopy was provided in respectively 142 and 89 cases; in the remaining (respectively 130 and 117 cases) such final proof was not provided.

${ }^{\mathrm{b}}$ Patients with colon cancer included.

patients. Only $27 \%$ of patients diagnosed with diabetes, ischemic heart disease or cerebrovascular disease (secondary prevention group; $n=105$ ) were on lipid lowering drugs. The others were not, although the majority of them (60 out of 77) had a total cholesterol (TC) $\geq 175 \mathrm{mg} / \mathrm{dl}$ ( $5 \mathrm{mmol} / \mathrm{l})$ and/or a low-density lipoprotein cholesterol (LDL-C) $\geq 100 \mathrm{mg} / \mathrm{dl}$ ( $3 \mathrm{mmol} / \mathrm{l}$ ). In the primary prevention group $(n=257)$, 9\% were on lipid lowering drugs. Another 68\%, however, had hypercholesterolaemia as well, defined as TC $\geq 190 \mathrm{mg} / \mathrm{dl}(4.5 \mathrm{mmol} / \mathrm{l})$ and/or LDL-C $\geq 115 \mathrm{mg} / \mathrm{dl}(2.5 \mathrm{mmol} / \mathrm{l})$ (18).

In patients treated by radiotherapy $(n=141)$, the prevalence of at least one pituitary deficiency was 73\%, compared with $23 \%$ in non-irradiated patients $(n=277 ; P<0.0001)$. Forty-nine malignant tumours were identified in $10.5 \%$ of patients with four patients having at least two malignancies. Breast, colon and haematological cancers were the most frequent ones (Table 3). Benign tumours other than colonic polyps and goitre were reported in $8.4 \%$ of patients. The prevalence of colonic polyps in the total cohort was $18.4 \%$. However, in 152 patients aged 50 or older, colonoscopy had not been performed or was not reported.

\section{Mortality}

Twenty-eight deaths $(6.7 \%)$ were reported in the period 2000-2004: 15 men at a median age of 68 years (range 39-84) and 13 women at a median age of 74 years (range 20-89). They had been diagnosed with acromegaly at a significantly older age (median of 48 years in men and 58 years in women) and a median of 14.5 years before the survey, in an era preceding the availability of somatostatin analogues and cabergoline. Of these patients, $50 \%(n=14)$ had undergone radiotherapy, when compared with $33 \%(n=127)$ in the
Table 3 Neoplasms in acromegaly (prevalence is calculated from the total registry of 418 cases).

\begin{tabular}{|c|c|c|}
\hline & $\begin{array}{l}\text { Prevalence } \\
\text { total }(\%)\end{array}$ & $n$ patients \\
\hline Benign (other than colon polyps) ${ }^{a}$ & 8.4 & 35 \\
\hline Malignancy & 10.5 & 44 \\
\hline Breast cancer $\mathrm{b}^{\mathrm{b}}$ & 7.3 & 15 \\
\hline $\begin{array}{l}\text { Prostate cancer or high grade } \\
\text { PIN }^{b}\end{array}$ & 1.9 & 4 \\
\hline Colon cancer & 1.9 & 8 (1 died) \\
\hline Haematological cancers $^{c}$ & 1.4 & 6 (1 died) \\
\hline Carcinoid (bronchial or liver) & 0.7 & 3 \\
\hline Gastric cancer & 0.5 & 2 (1 died) \\
\hline Other malignant neoplasms ${ }^{d}$ & 2.6 & 11 ( 2 died) \\
\hline
\end{tabular}

ancluding the following benign tumours: Lipoma (8), uterine fibroma (5), ovarian cyst or other benign neoplasm (5), meningioma (3), parathyroid adenoma (3), duodenal or intestinal polyp (2), insulinoma (1), adrenal adenoma (1), hepatic adenoma (1), cholesteatoma (1), cerebral cavernous angioma (1), schwannoma (1), benign breast tumour (1), prostate hypertrophy (1), thyroid follicular adenoma (1), fibrocystic bone hypertrophy (1) and polycystic renal disease (1).

${ }^{b}$ In women (breast) or men (prostate) only.

'Including non-Hodgkin's lymphoma (3, 1 death), chronic leukaemia (2) and myelofibrosis (1).

dIncluding the following cancers: kidney (2), larynx (1), lung (1, death), oesophagus (1), pancreas (1), endometrial (2, 1 death), ovarian (1), retinal melanoma (1), skin (1).

remainder of the cohort $(P=0.06)$. There was, however, no difference in the prevalence of hypopituitarism between the two groups (43 and $40 \%$ respectively).

The deceased patients had suffered more frequently from diabetes ( $41 \%$ of 27 reported), cardiovascular ( $50 \%$ of 26 reported) or cerebrovascular $(30 \%$ of 23 reported) disease, and malignancy (prevalence 36\%) than the total cohort. Causes of death were cancer $(n=5)$, pneumonia $(n=3)$, cerebrovascular $(n=5)$ or cardiovascular $(n=7)$ diseases, miscellaneous $(n=4)$ or unknown $(n=4)$.

A total of 1822 patient-years of follow-up from 1 January 2000, or year of diagnosis in new cases, was available for comparison with normative data of the Belgian population. All-cause mortality was higher in the patients, although not significantly when compared with the general population $(\mathrm{SMR}=27 / 19.4=1.39$ (95\% CI 0.96-2.03); $P=0.14)$. In patients treated by radiotherapy $(n=141)$, all-cause mortality was, however, significantly increased $(\mathrm{SMR}=14 / 5.2=2.70$ (95\% CI 1.60-4.55); $P=0.02$ ), while it was normal in the non-irradiated patients $(n=274 ; \mathrm{SMR}=13 / 14.2=$ $0.92(95 \%$ CI $0.53-1.58) P=0.74)$. Access to $\mathrm{GH}$ lowering drugs while awaiting the results of the radiotherapy (patients diagnosed after 1990) had no significant effect on the excess mortality (Table 4).

\section{Therapy}

The combinations of treatment modalities in this retrospectively identified cohort are listed in Table 5. Sixty-eight percent $(n=286)$ of the patients underwent 321 surgical procedures, mostly by the transsphenoidal 
Table 4 Prevalence of cerebrovascular disease and standardised mortality ratios (SMR) in irradiated and non-irradiated patients.

\begin{tabular}{|c|c|c|c|c|c|c|c|}
\hline \multirow[b]{2}{*}{$\begin{array}{l}\text { Year of } \\
\text { diagnosis }\end{array}$} & \multicolumn{3}{|c|}{ With radiotherapy } & \multicolumn{4}{|c|}{ No radiotherapy } \\
\hline & $\begin{array}{c}\text { Cerebro- } \\
\text { vascular } \\
\text { disease }(\%)\end{array}$ & $\begin{array}{c}\text { Number of } \\
\text { deaths }\end{array}$ & $\begin{array}{c}\text { SMR } \\
(95 \% \mathrm{Cl})\end{array}$ & $\begin{array}{c}\text { Cerebro- } \\
\text { vascular } \\
\text { disease (\%) }\end{array}$ & $\begin{array}{l}\text { Number of } \\
\text { deaths }\end{array}$ & $\begin{array}{c}\text { SMR } \\
(95 \% \mathrm{Cl})\end{array}$ & \\
\hline All patients & 9.9 & 14 of 141 & $2.70(1.60-4.55) P=0.02$ & 4.7 & 13 of 274 & $0.92(0.53-1.58)$ & $P=0.74$ \\
\hline$<1990(n=139)$ & 13.3 & 10 of 76 & $2.63(1.42-4.90) P=0.059$ & 6.3 & 4 of 63 & $0.73(0.27-1.94)$ & $P=0.46$ \\
\hline$\geq 1990(n=276)$ & 6.2 & 4 of 65 & $2.88(1.08-7.67) P=0.21$ & 4.3 & 9 of 211 & $1.04(0.54-1.99)$ & $P=0.92$ \\
\hline
\end{tabular}

Three patients living in the Mediterranean region were excluded from the SMR analysis. For calculation of $\mathrm{SMR}, \mathrm{Cl}$ and $P$ values, see Materials and methods section.

route $(>85 \%)$, even in patients requiring a second $(n=25)$ or third surgery $(n=5)$. Sixty-four percent of surgical procedures were performed in the reporting centre, the remaining surgeries in one of the other participating centres $(n=53)$, in a non-participating Belgian hospital $(n=45$, of which 38 were in CHU Liège), abroad $(n=13)$ or unknown $(n=3)$. Over the last decade, the use of pituitary surgery has declined (Fig. 2). Radiotherapy had been used in 34\% of cases $(n=141)$, mostly as an adjunctive therapy after surgery. With the exception of two yttrium implants in the 1960s and three cases of radiosurgery, radiotherapy was conventional. In $70 \%$ of the cases, adjunctive radiotherapy was administered after 1990. Primary radiotherapy, however, had been almost abandoned by 1994. Overall, $26 \%$ of the patients $(n=108)$ never had any pituitary-directed therapy (surgery or radiotherapy), including those with recent diagnosis.

The majority of patients $(n=324$ or $78 \%)$ received medical treatment at some time. Of these, $19 \%$ had been treated with the dopamine agonists (DA) bromocriptine and/or cabergoline $(n=62), 42 \%$ with different shortand long-acting somatostatin analogues (SSA) $(n=134)$ and $39 \%$ with both DA and SSA $(n=123)$, either sequentially or in combination. In addition, four patients had commenced with the GH receptor antagonist (GHRA) pegvisomant as part of a clinical trial starting in 2003.
Among the actively participating patients, 208 (58\%) were on medical treatment at the time of the survey, most commonly SSA ( $n=148$, mostly long-acting SSA: lanreotide Autogel in 51\% and octreotide LAR in 45\%), followed by DA ( $n=40$, of whom $77 \%$ were treated with cabergoline), both $(n=16)$ or finally pegvisomant $(n=4)$. Another 10 patients, considered GH deficient as a consequence of their previous surgery $(n=4)$, radiotherapy $(n=1)$ or both $(n=5)$, were on $\mathrm{GH}$ replacement therapy.

\section{Biochemical outcome}

Centralised determinations of GH and IGF-I were available in 316 of the 362 patients who actively participated in the survey. In all but 7 of the remaining 46 survey patients, local measurements of $\mathrm{GH}(n=30)$ and/or IGF-I $(n=35)$ were available. However, in less than half $(48 \%)$ of the 56 patients that were lost to follow-up or had died, a last IGF-I value with or without $\mathrm{GH}$ was provided.

Table 6 summarises the outcome of the different treatment regimens in patients with central laboratory determinations. The cure rate of surgery, by the strict definition of both normal IGF-I for age (SDS $\leq 2)$ and safe GH $(\leq 2 \mu \mathrm{g} / \mathrm{l})$, was $34 \%(n=125$ patients $)$. The cure rate was not higher in patients operated in nonparticipating centres. A similar cure rate $(34 \%)$ was

Table 5 Therapeutic modalities used in patients with acromegaly.

\begin{tabular}{|c|c|c|c|c|}
\hline & \multicolumn{2}{|c|}{ Total cohort } & \multicolumn{2}{|c|}{ Tumour size (\%) ${ }^{\mathrm{a}}$} \\
\hline & $N(\%)$ & $N(\%)$ & Macroadenoma & Microadenoma \\
\hline Surgery & $169(40)$ & & 79 & 17 \\
\hline Subgroup + medical ever & & $117(28)$ & 80 & 19 \\
\hline Surgery + radiotherapy & $117(28)$ & & 92 & 3 \\
\hline Subgroup + medical ever & & $97(23)$ & 93 & 2 \\
\hline Radiotherapy & $24(6)$ & & 75 & 13 \\
\hline Subgroup + medical ever & & $15(4)$ & 80 & 13 \\
\hline Primary medical & $95(23)$ & $95(23)$ & 64 & 28 \\
\hline Never or not yet treated ${ }^{b}$ & $13(3)$ & & 69 & 23 \\
\hline Total & $418(100)$ & & 79 & 16 \\
\hline Total of patients ever treated medically & & $324(78)$ & 79 & 16 \\
\hline
\end{tabular}

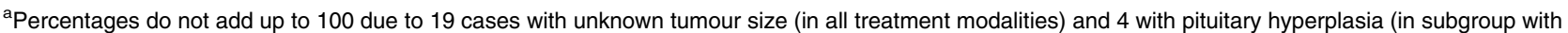
primary medical treatment).

Including 10 with recent diagnosis and 1 death shortly after diagnosis. 


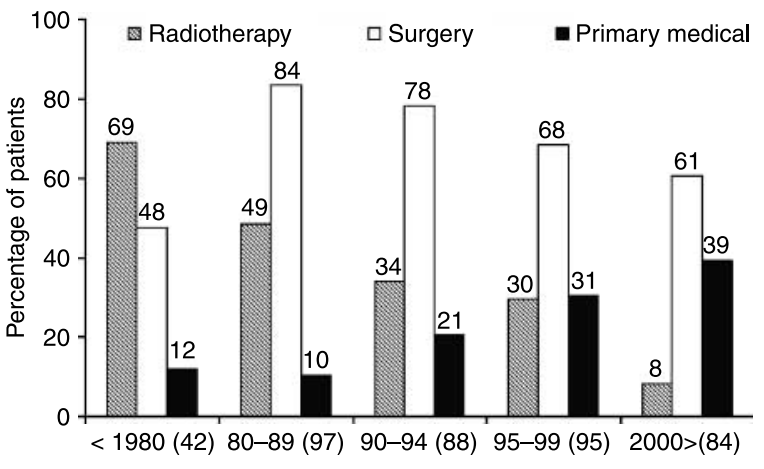

Figure 2 Percentage of patients treated by radiotherapy, surgery or by primary medical treatment according to year of diagnosis. Number of patients diagnosed within the indicated period given in parentheses. Twelve patients with recent diagnosis in whom treatment had not yet been initiated were excluded from the analysis.

observed in patients treated by surgery and radiotherapy $(n=92)$. Radiotherapy alone, administered a median of 29 years (mean 27; range 10-43) before the survey, normalised both parameters in $50 \%$ of 20 patients. The majority (79\%) of patients not cured by surgery and/or radiotherapy $(n=154)$ were on medical therapy at the time of the survey. This adjunctive medical therapy $(n=121)$ normalised IGF-I in $53 \%$, GH in $59 \%$ and both parameters in $42 \%$. In contrast, primary medical therapy $(n=74)$ normalised IGF-I in $31 \%$, GH in $51 \%$, and both in only $24 \%$. Patients treated with DA alone did worse, both on primary $(n=14$, control in 13\%) or adjunctive $(n=25$, control in $32 \%)$ medical therapy than those on SSA (control in $28 \%$ of 57 cases versus $45 \%$ of 94 cases in primary and adjunctive therapy respectively).

Thus, $43 \%$ of patients with multimodal treatment (surgery/radiotherapy \pm pharmacotherapy) and 76\% on primary medical therapy still had an elevated IGF-I and/or a non-safe GH $(P<0.0001)$. Overall, IGF-I was normal in $56 \%$ (175 out of 311 ) and GH was safe in $65 \%$ (201 out of 307) of the treated patients. Cure or control (fulfilling both criteria) was obtained in $49 \%$.

Fifty-four percent of survey patients without central lab determination $(n=46)$ were in follow-up in smaller centres (without radiotherapy department). Treatment modalities and outcome differed in several respects: more surgery and less adjuvant radiotherapy or primary medical therapy (57\% surgery, $17 \%$ surgery + radiotherapy, $13 \%$ primary medical, $13 \%$ not (yet) treated). At the time of the survey, only $30 \%$ were on medical therapy. Cure rate of surgery alone was estimated at $50 \%$ in the 24 patients for whom local IGF-I and/or GH values were provided. The frequency of pituitary deficiencies was lower at $26 \%$ (12 out of 46 ).

There were no significant differences between survey patients and lost-to-follow-up patients (15 men, 16 women) regarding age at diagnosis, duration of follow-up or frequency of surgery (68\%). Lost patients had received less radiotherapy (adjuvant in $26 \%)$ and had less pituitary deficiencies, $32 \%$ (10

Table 6 Percentage of patients with normal insulin-like growth factor-I (IGF-I), safe growth hormone (GH) or both, stratified by past and current treatments (subgroup receiving medical therapy).

\begin{tabular}{|c|c|c|c|c|c|c|c|}
\hline \multirow[b]{2}{*}{ Therapy ( $\%$ with macroadenoma) } & \multirow[b]{2}{*}{ Patients $n$} & \multirow[b]{2}{*}{$\begin{array}{c}\text { Normal } \\
\text { IGF-I } \\
(\leq 2 \text { SDS }) \\
(\%)\end{array}$} & \multirow[b]{2}{*}{$\begin{array}{l}\text { Safe } \mathbf{G H}^{\mathrm{a}} \\
(\leq 2 \mu \mathrm{g} / \mathrm{l}) \\
(\%)\end{array}$} & \multicolumn{2}{|c|}{$\begin{array}{c}\text { Both normal IGF-I and } \\
\text { safe GH }\end{array}$} & \multicolumn{2}{|c|}{ Not controlled } \\
\hline & & & & $\begin{array}{c}\text { Cured } \\
(\%)\end{array}$ & $\begin{array}{l}\text { Controlled } \\
(\%)\end{array}$ & $\begin{array}{c}\text { Active } \\
\text { disease (\%) }\end{array}$ & $\begin{array}{c}\text { Discordant } \\
\text { GH and IGF-I } \\
(\%)\end{array}$ \\
\hline Surgery all patients (82) & 125 & 36 & 36 & 34 & & & \\
\hline + Adjunctive medical therapy (89) & 65 & 52 & $56^{\mathrm{b}}$ & & 37 & 26 & 35 \\
\hline Surgery + radiotherapy all (92) & 92 & 36 & 39 & 34 & & & \\
\hline + Adjunctive medical therapy (94) & 52 & 59 & 65 & & 52 & 31 & 17 \\
\hline Radiotherapy all (80) & 20 & 50 & 70 & 50 & & & \\
\hline + Adjunctive medical therapy (75) & 4 & 25 & 25 & & 0 & 50 & 50 \\
\hline Subtotal multimodal treatment (86) & 237 & 37 & 40 & 35 & 22 & 20 & 23 \\
\hline+ Adjunctive medical therapy (91) & 121 & 53 & $59^{\mathrm{b}}$ & & 42 & 30 & 28 \\
\hline SSA (+DA in 10) & 94 & & & & 45 & 29 & 27 \\
\hline DA alone & 25 & & & & 32 & 32 & 36 \\
\hline Primary medical therapy (65) & 74 & 31 & $51^{\mathrm{b}}$ & & 24 & 42 & 34 \\
\hline SSA (+DA in 2) & 57 & & & & 28 & 35 & 37 \\
\hline DA alone & 15 & & & & 13 & 60 & 27 \\
\hline Total group (global outcome) (81) & 311 & 56 & $66^{\mathrm{b}}$ & 27 & 22 & 25 & 26 \\
\hline Not yet treated (recent diagnosis) (80) & 5 & & & & & & \\
\hline
\end{tabular}


out of 31). IGF-I was normal in 9 out of the 10 surgery patients in whom this test was available at the last visit, suggesting that patients cured by surgery may more likely discontinue follow-up.

\section{Discussion}

Our survey retrospectively identified a cohort of 418 patients with acromegaly, alive on 1 January 2000, in follow-up or newly diagnosed in an endocrine centre in Belgium or GD-Luxembourg. However, not all endocrinologists involved in acromegaly participated, thus precluding inclusion of all patients. Based on the Belgian population count and the highest prevalence of acromegaly recorded (59 c.p.m.), which is similar to the average prevalence of 58 c.p.m. reported by Holdaway et al. (19), we assume to have included three-quarters and half of cases in the Flemish and French speaking regions respectively. We are probably also missing cured patients who withdrew from endocrine care before 2000, as suggested by the lower prevalence of microadenoma in cases diagnosed before that date. This view is supported by a higher surgical cure rate in the lost-to-follow-up group, although a higher diagnostic awareness may also explain the increased prevalence of microadenomas.

In contrast with the most extensive registry published to date, the Spanish Acromegaly Registry REA (12), in which the different co-morbidities were not reported in $15-60 \%$, the nature of our registry (a survey) prompted participants to provide data on morbidity in almost all patients, except for colonic polyps and to a lesser degree gallstones and sleep apnoea. More active inquiring may explain the higher reported prevalence of arthopathy (47 vs $20 \%$ in REA) and possibly carpal tunnel syndrome (28 vs $19 \%$ ) but not of gallstones (23 vs $9.5 \%$ in REA). Even if the use of SSA is taken into account, the prevalence of gallstones in our cohort is twice as high ( 31 vs $15.5 \%$ of SSA-exposed and 8 vs $4.1 \%$ of non-exposed patients in AcroBel and REA respectively), but without attaining the $26 \%$ before and $47 \%$ after octreotide, reported in a study of 49 patients (20). This difference is probably due to selection bias as ultrasound is not systematically performed in every day clinical care, especially if patients are not treated with SSA. On the other hand, the reported prevalence of overt diabetes mellitus (25\%), previously reported to be 9-23\% (19), is lower than in REA (38\%) and in a Canadian study (40\%) (8). Underreporting is unlikely, as the non-diabetic patients had normal glucose and $\mathrm{HbA1c}$ values at the time of the survey.

Colonic polyps as reported by the physicians were present in $27 \%$. However, if the denominator is limited to $40 \%$ of the cohort in whom a colonoscopy was reported, colonic polyps were present in $46 \%$, in agreement with the $40-45 \%$ prevalence reported in prospective studies as reviewed by Jenkins (21) and Melmed (22). Prevalence in REA was much lower $(9.5 \%$ of patients with a colonoscopy, performed in $42 \%$ of their cases). The prevalence of cancers was also higher than reported in REA, but in agreement with the data of the largest epidemiological study published so far (3).

Median age at death in the Belgian survey (68 years in men and 74 years in women) is higher than reported in previous series: 60 years in REA (12), 61 years in Quebec (8) and New Zealand (6), but close to the 64 years for men and 69 years for women in Finland (5) and the 66 years in the West Midlands database (4). By comparison, current life expectancy in Belgium is 75.6 in men and 81.7 years in women. The prevalence of respiratory death $(11 \%)$ was comparable, but death from malignancy $(18 \%)$ was less frequent than previously reported $(22-24 \%)(3,4,12)$. Cerebrovascular death $(18 \%)$ was more frequent than reported by Orme (3) and Mestrón (12) (12\%), and closer to the data of Ayuk (21\%) (4). Cardiovascular death (in 25 vs $36-39 \%$ in previous studies) was probably underreported as three-quarters of patients with unknown cause of death (14\%) were suffering from diabetes and coronary heart disease. Due to the low number of deaths, our study misses the power to show a significant difference in all-cause mortality at the observed SMR of 1.39 (95\% CI 0.96-2.03). This result is, however, comparable with the significantly increased mortality (SMR 1.26; CI 1.03-1.54) reported in a cohort of 419 acromegalic patients of the West Midlands Pituitary Database, with a follow-up of 12 years and a total number of deaths 3.5 times that observed in our cohort over 5 years (4).

Nevertheless, in the subgroup of irradiated patients, mortality was significantly increased (SMR 2.7), confirming data reported by Ayuk (SMR 1.58) and from Finland (SMR 1.69) (5). In contrast, the mortality observed in the non-irradiated patients in all three studies was not different from the general population (SMR of 0.92, 0.95 and 0.94 respectively). Likewise, in the Spanish registry, the probability of having received radiotherapy was 2.3 greater in deceased patients than in survivors (12). Hypopituitarism is a well-known consequence of pituitary irradiation (23) and has been implicated in the excess mortality of non-functioning pituitary adenomas (24). The present study indeed showed a higher prevalence of at least one pituitary deficit in the irradiated patients, but no difference in the prevalence of hypopituitarism between deceased patients and survivors, suggesting that factors other than hypopituitarism might be involved. Also in REA, there was no correlation of mortality with hypopituitarism (12). Since the majority of the deceased patients had died before the survey period, centrally determined IGF-I and GH values were not available and the effect of hormonal control could not be evaluated in this subset of patients.

Our survey also illustrates the changing pattern of therapy over the last decades in newly diagnosed acromegaly (Fig. 2); the switch from radiotherapy to transsphenoidal surgery as a primary treatment in the 
1980s, followed by a further reduction in the use of radiotherapy in the $90 \mathrm{~s}$ as somatostatin analogues became available as adjuvant therapy to incomplete surgery. At variance with countries like Finland, where the proportion of operated patients has remained elevated $(90 \%)(5)$, the use of surgery in our survey patients has declined in favour of primary medical therapy. This trend parallels the participation of the university hospitals in clinical trials evaluating the different formulations of SSA from the early 1990s onwards.

One of the major strengths of our registry is the availability of centralised GH and IGF-I measurements in 316 patients, allowing a standardised evaluation of the outcome of different treatment strategies. In agreement with the consensus statement (10), stringent biochemical criteria were used to define cure or control (when obtained under medical therapy): the combination of an IGF-I within an age-adjusted normal range and a mean $\mathrm{GH} \leq 2 \mu \mathrm{g} / \mathrm{l}$, using the recently proposed cut-off with old GH standards $(4,25,26)$. The outcome parameters reported here are poorer than in most previous studies but are not surprising with respect to the less strict criteria for cure or control in other studies and the publication bias of non-superior results. Our cross-sectional evaluation of a non-selected cohort of patients at various time intervals after diagnosis does not assess the efficacy (as in randomised control trials) but rather the 'real-life' effectiveness of the different treatments. In addition, since we did not collect data on immediate surgical outcome and about $80 \%$ of surgical procedures had been performed 5 years or more before assessment, the surgical cure rate of $34 \%$ needs to be compared with long-term follow-up data of surgical series including a similar proportion of macroadenomas and using similar strict biochemical criteria. Such conditions are fulfilled in the study of Biermasz et al. who observed a similar control rate $(37 \%)$ after 10 years, but a much better figure $(60 \%)$ when analysed early after surgery (27). Nevertheless, the global cure or control rate of $49 \%$ found in AcroBel is similar to that observed in the West Midlands database $(46 \%$ of 360 patients had both normal IGF-I and $\mathrm{GH}<2 \mu \mathrm{g} / \mathrm{l})(4)$. In the larger Spanish database REA, using less strict criteria and multiple assays, cure was reported in 35\% of 1084 evaluated patients (12). Finally, in the Finnish database, results derived from the GH data ( $55 \%$ of $314<2.5 \mu \mathrm{g} / \mathrm{l}$ ) and IGF-I data (normal in $55 \%$ of 241 ) were not combined, but it is likely that the global control rate using both criteria was also below $50 \%(5)$.

Following reports that octreotide was equally effective in primary and adjuvant therapy $(28,29)$ and considering the disappointing results of surgery in macroadenomas and invasive adenomas, primary medical therapy with SSA has recently been advocated as a first-line therapeutic choice for acromegalic patients not amenable to surgical cure (30). However, only $24 \%$ of 74 patients on primary medical therapy fulfilled both criteria of control versus $42 \%$ of 121 patients on secondary medical therapy. Even after exclusion of patients not using SSA, i.e. monotherapy with DA or pegvisomant, the rate of control under primary medical therapy in our 'real-life' setting $(28 \%$ in 57 patients) remains lower than the results reported in two Italian series $(42.4 \%$ after 1 year (31) and $57 \%$ after a median of 4 years (30) of therapy with SSA using a random $\mathrm{GH} \leq 2.5 \mu \mathrm{g} / \mathrm{l}$ as cut-off with a normal IGF-I). This is possibly due to the lower cut-off for GH used in our study, the non-selection of patients before treatment, differences in duration of therapy or in SSA dosing ( $48 \%$ were on $30 \mathrm{mg}$ LAR versus $67 \%$ in the Cozzi study (30)), and a lower patient compliance outside the setting of a controlled trial. Moreover, our outcome analysis is based on one blood sampling and not on the lowest level of GH and IGF-I achieved during the course of therapy.

Gross debulking of invasive tumours has recently been reported to increase the percentage of patients attaining random $\mathrm{GH} \leq 2.5 \mu \mathrm{g} / \mathrm{l}$ (from 14 to $56 \%$ ) or normal IGF-I (from 10 to $55 \%$ ) during primary and secondary therapy with SSA (32). Furthermore, studies showing a comparable efficacy of primary and secondary treatment with long-acting SSA in terms of remission rates in macroadenomas with extrasellar extension (33) often do not take into account the additive effect of remission by surgery $(31 \%$ in this series). Likewise, the best results in our survey $(57 \%$ cure or control) were obtained when surgery/radiotherapy was combined with medical treatment in noncured patients, while $76 \%$ of patients on primary medical therapy still had an elevated IGF-I and/or a non-safe GH.

In conclusion, although the Belgian registry is small when compared with those of larger European countries, we were able to provide a real-life picture of acromegaly by including smaller centres treating patients with acromegaly. The survey nature of this platform assured a more complete data collection, while the provision of a centralised GH and IGF-I measurement allowed a cross-sectional standardised evaluation of the level of control obtained in patients attending the endocrine clinic in 2003-2004. Cure or control, defined by the stringent criteria of both a low $\mathrm{GH} \leq 2 \mu \mathrm{g} / \mathrm{l}$ and a normal IGF-I, was obtained in about $50 \%$ of the treated patients. Further improvement will certainly be obtained by offering debulking surgery to non-operated patients, by optimising the dosage of the SSA therapy, and by the recent introduction of the GHRA pegvisomant in the treatment algorithm in Belgium.

\section{Acknowledgements}

Sponsorship was provided by an unrestricted grant from Novartis Belgium. We gratefully acknowledge the 
support of the Belgian Endocrine Society and the following investigators contributing to the database:

$\mathrm{G}$ Michel (CH Luxembourg, GD-Luxembourg), E Couturier (CHU Saint Pierre, Brussels), G Copinschi, B Corvilain, F Fery, J Mockel (ULB Erasme, Brussels), C Gillet, R Karmali (CHU Brugmann, Brussels), K Poppe, B Velkeniers (AZ VUB, Jette), O Alexopoulou, D Maiter (Cliniques Universitaires Saint-Luc, Woluwe), V Col, J-F Vanderijst (Clinique St-Pierre, Ottignies), A Verhaegen (AZ Jan Palfijn, Antwerpen), M Verhaert (AZ Sint Vincentius, Antwerp), J Verhelst (AZ Middelheim, Antwerp), M-C Pelckmans (AZ Sint Maarten, Mechelen), HBecq, W Vinck (AZ Sint-Augustinus, Wilrijk), P Abrams, R Abs (University Hospital Antwerp, Edegem), C Vercammen (Imelda Ziekenhuis, Bonheiden), M Bex, R Bouillon (University Hospital Gasthuisberg, Leuven), J-L Coolens (CAZ Midden Limburg Salvator, Hasselt), Y Kockaerts, J Tits (ZOL André Dumont Genk), J Gerard (CH Saint Joseph, Liège), B Remacle (Clin. St Joseph Espérence, Saint-Nicolas (Lg)), C Righes (CH Peltzer - La Tourelle, Verviers), A-S Dramais (Clinique Saint Elisabeth, Namur), L Derdelinckx (Clinique Saint Luc, Bouge), E Delgrange, J Donckier, F Heureux (UCL Mont Godinne, Godinne), J-C Daubresse, C Lemy, G Krzentowski (CHU Charleroi, Charleroi), D Scarnière (Sint Joseph Gilly, Charleroi), E Duvivier, P Levecque (Clinique Notre dame Reine Fabiola Montignies, Charleroi), Y De Houck (Clinique Saint Joseph, Arlon), I Colin (CHR - Saint Joseph, Mons), J Ducobu (CHU Tivoli, La Louvière), G Lamberigts, A Van den Bruel, S Van Imschoot (AZ Sint-Jan, Brugge), A Beirinckx (AZ Sint-Lucas, Brugge), D Nicolaij, J Schutyser (AZ Groeninge, Kortrijk), E Vanfleteren (Sint Jozefskliniek, Izegem), A Carlier, P Taelman (AZ Maria Middelares, Gent) S Haemers, C Tuyttens (AZ Sint-Lucas, Gent), R Rubens, G T'Sjoen, M Vande Weghe (University Hospital Gent, Gent), D Van Nimmen (AZ Sint Blasius, Dendermonde), F Nobels, P Van Crombrugge (O L V Ziekenhuis, Aalst).

\section{References}

1 Melmed S. Acromegaly. New England Journal of Medicine 2006355 2558-2573.

2 Bates AS, Van't Hoff W, Jones JM \& Clayton RN. An audit of outcome of treatment in acromegaly. Quarterly Journal of Medicine $199386293-299$.

3 Orme SM, McNally RJQ, Cartwright RA, Belchetz PE for the United Kingdom Acromegaly Study Group Mortality and cancer incidence in acromegaly: a retrospective cohort study. Journal of Clinical Endocrinology and Metabolism $1998 \mathbf{8 3} 2730-2734$.

4 Ayuk J, Clayton RN, Holder G, Sheppard MC, Stewart PM \& Bates AS. Growth hormone and pituitary radiotherapy, but not serum insulin-like growth factor-I concentrations, predict excess mortality in patients with acromegaly. Journal of Clinical Endocrinology and Metabolism 200489 1613-1617.

5 Kauppinen-Mäkelin R, Sane T, Reunanen A, Välimäki PJ, Niskanen L, Markkanen H, Löyttyniemi E, Ebeling T, Jaatinen P, Laine H, Nuutila P, Salmela P, Salmi J, Stenman UF, Viikari J \&
Voutilainen E. A nationwide survey of mortality in acromegaly. Journal of Clinical Endocrinology and Metabolism 2005904081 4086.

6 Holdaway IM, Rajasoorya RC \& Gamble GD. Factors influencing mortality in acromegaly. Journal of Clinical Endocrinology and Metabolism 200489 667-674.

7 Swearingen B, Barker FG II, Katznelson L, Biller BMK, Grinspoon S, Klibanski A, Moayeri N, Black PMCL \& Zervas NT. Long-term mortality after transsphenoidal surgery and adjunctive therapy for acromegaly. Journal of Clinical Endocrinology and Metabolism 1998 83 3419-3426.

8 Beauregard C, Truong U, Hardy J \& Serri O. Long-term outcome and mortality after transsphenoidal adenomectomy for acromegaly. Clinical Endocrinology 200258 86-91.

9 Biermasz NR, Dekker FW, Pereira AM, van Thiel SW, Schutte PJ, van Dulken H, Romijn JA \& Roelfsema F. Determinants of survival in treated acromegaly in a single center: predictive value of serial insuline-like growth factor I measurements. Journal of Clinical Endocrinology and Metabolism 200489 2789-2796.

10 Guistina A, Barkan A, Casanueva FF, Cavagnini F, Frohman L, Ho K, Veldhuis J, Wass J, Von Werder K \& Melmed S. Criteria for cure of acromegaly: a consensus statement. Journal of Clinical Endocrinology and Metabolism 200085 526-529.

11 Katznelson L, Kleinberg D, Vance ML, Stravou S, Mulaski KJ, Schoenfeld DA, Hayden DL, Wright ME, Woodburn CJ \& Klibanski A. Hypogonadism in patients with acromegaly: data from the multi-centre acromegaly registry pilot study. Clinical Endocrinology $2000 \mathbf{5 4} 183-188$.

12 Mestrón A, Webb SA, Astorga R, Benito P, Catala M, Gaztambide S, Gomez JM, Halperin I, Lucas-Morante T, Moreno B, Obiols G, de Pablos P, Paramo C, Pico A, Torres E, Varela C, Vasquez JA, Zamora J, Albareda M, Gilabert M \& on behalf of all the REA participants. Epidemiology, clinical characteristics, outcome, morbidity and mortality in acromegaly based on the Spanish Acromegaly Registry (Registro Español de Acromegalia, REA). European Journal of Endocrinology 2004 151 439-446.

13 Reincke M, Petersenn S, Buchfelder M, Gerbert B, Skrobek-Engel G, Franz H, Lohmann R \& Quabbe HJ. The German Acromegaly Registry: description of the database and initial results. Experimental and Clinical Endocrinology and Diabetes 2006114 498-505.

14 Drange MR, Fram NR, Herman-Bonert V \& Melmed S. Pituitary tumor registry: a novel clinical resource. Journal of Clinical Endocrinology and Metabolism 200085 168-174.

15 Webb SM, Prieto L, Badia X, Albareda M, Catala M, Gaztambide S, Lucas T, Paramo C, Pico A, Lucas A, Helperin I, Obiols G \& Astorga R. Acromegaly Quality of Life Questionnaire (ACROQOL) a new health-related quality of life questionnaire for patients with acromegaly: development and psychometric properties. Clinical Endocrinology 200257 251-258.

16 T'Sjoen G, Bex M, Maiter D, Velkeniers B \& Abs R. Health related quality of life in acromegalic subjects: data from AcroBel, the Belgian registry on acromegaly. European Journal of Endocrinology $2007157411-417$.

17 Brabant G, von zur Mühlen A, Wüster C, Ranke MB, Kratzsch J, Kiess W, Ketelslegers JM, Wilhemsen L, Hulthén L, Saller B, Mattsson A, Wilde J, Schemer R, Kann P; on behalf of the German KIMS Board. Serum insulin-like growth factor I reference values for an automated chemiluminescence immunoassay system: results from a multicenter study. Hormone Research 2003 $6053-60$.

18 De Backer G, Ambrosioni E, Borch-Johnsen K, Brotons C, Cifkova R, Dallongeville J, Ebrahim S, Faergeman O, Graham I, Mancia G, Cats VM, Orth-Gomer K, Perk J, Pyorala K, Rodicio JL, Sans S, Sansoy V, Sechtem U, Silber S, Thomsen T \& Wood D; European Society of Cardiology, American Heart Association, American College of Cardiology. European guidelines on cardiovascular disease prevention in clinical practice. Third Joint Task Force of European and other Societies on Cardiovascular Disease Prevention in Clinical Practice. Atherosclerosis 2004173 381-391.

19 Holdaway IM \& Rajasoorya C. Epidemiology of acromegaly. Pituitary 19992 29-41. 
20 Montini M, Gianola D, Pagani MD, Pedroncelli A, Caldara R, Gherardi F, Bonelli M, Lancranjan I \& Pagani G. Cholelithiasis and acreomagly: therapeutic strategies. Clinical Endocrinology $1994 \mathbf{4 0}$ 401-406.

21 Jenkins PJ \& Besser M. Acromegaly and cancer: a problem. Journal of Clinical Endocrinology and Metabolism 200186 2935-2941.

22 Melmed S. Acromegaly and cancer: not a problem? Journal of Clinical Endocrinology and Metabolism $2001862929-2934$.

23 Darzy KH \& Shalet SM. Hypopituitarism as a consequence of brain tumours and radiotherapy. Pituitary 20058 203-211.

24 Tomlinson JW, Holden N, Hills RK, Wheatley K, Clayton RN, Bates AS, Sheppard MC \& Stewart PM Association between premature mortality and hypopituitarism. The West Midlands Prospective Hypopituitary Study Group. Lancet $20013 \mathbf{3 5 7}$ 425-431.

25 Biochemical assessment and long term monitoring in patients with acromegaly: statement from a Joint Consensus Conference of the Growth Hormone Research Society and the Pituitary Society. Journal of Clinical Endocrinology and Metabolism $2004 \mathbf{8 9}$ 3099-3102.

26 Ronchi CL, Varca V, Giavoli C, Epaminonda P, Beck-Peccoz P, Spada A \& Arosio M. Long-term evaluation of postoperative acromegalic patients in remission with previous and newly proposed criteria. Journal of Clinical Endocrinology and Metabolism $2005901377-1382$.

27 Biermasz NR, van Dulken H \& Roelfsema F. Ten-year follow-up results of transsphenoidal microsurgery in acromegaly. Journal of Clinical Endocrinology and Metabolism $2000 \mathbf{8 5}$ 4596-4602.

28 Newman CB, Melmed S, George A, Torigian D, Duchaney M, Snyder P, Young W, Klibanski A, Molitch ME, Gagel R, Sheeler L, Cook D, Malarkey W, Jackson I, Vance ML, Barkan A, Frohman L \& Kleinberg DL. Octreotide as primary therapy for acromegaly. Journal of Clinical Endocrinology and Metabolism $1998 \mathbf{8 3}$ 3034-3040.
29 Freda PU, Katznelson L, vander Lely AJ, Reyes CM, Zhao S \& Rabinowitz D. Long-acting somatostatin analog therapy of acromegaly: a meta-analysis. Journal of Clinical Endocrinology and Metabolism 200590 4465-4473.

30 Cozzi R, Montini M, Attanasio R, Albizzi M, Lasio G, Lodrini S, Doneda P, Cortesi L \& Pagani G. Primary treatment of acromegaly with octrotide LAR: a long-term (up to nine years) prospective study of its efficacy in the control of disease activity and tumor shrinkage. Journal of Clinical Endocrinology and Metabolism 2006 91 1397-1403.

31 Colao A, Pivonello R, Auriemma RS, Briganti F, Galdiero M, Tortora F, Caranci F, Cirillo S \& Lombardi G. Predictors of tumor shrinkage after primary therapy with somatostatin analogs in acromegaly: a prospective study in 99 patients. Journal of Clinical Endocrinology and Metabolism $2006912112-2118$.

32 Colao A, Attanasio R, Pivonello R, Cappabianca P, Cavallo LM, Lasio G, Lodrini A, Lombardi G \& Cozzi R. Partial surgical removal of growth hormone-secreting pituitary tumors enhances the response to somatostin analogs in acromegaly. Journal of Clinical Endocrinology and Metabolism 200691 85-92.

33 Jaquet P, Cortet-Rudelli Ch, Sassolas G, Morange-Ramos I, Chanson P, Brue T, Andrieu JP, Beckers A, Bertherat J, BorsonChazot F, Brassier G, Caron P, Cogne M, Cottier JP, Delemer B, Dufour H, Enjalbert A, Figarella Branger D, Gaillard R, Gueydan M, Jan M, Kuhn JM, Raingeard I, Regis J, Roger P, Rohmer V, Sadoul JL, Saveanu A, Tabarin A, Travers N, Trouillas J \& the French Acromegaly Registry. Therapeutic strategies in somatotroph adenomas with extrasellar extension: role of the medical approach, a consensus study of the French Acromegaly Registry. Annales d'Endocrinologie 200364 434-441.

Received 31 May 2007

Accepted 23 July 2007 